\title{
Polymyositis with plasma cell infiltrate in essential mixed cryoglobulinaemia
}

\author{
Christopher Voll, Lee C Ang, John Sibley, Robert Card, Kim Lefevre
}

\begin{abstract}
A patient with essential cryoglobulinaemia who presented with polymyositis is described. Muscle biopsy showed intense plasma cell infiltration of muscle. Plasmapheresis produced a rapid resolution of the cutaneous manifestations of the disease, but little improvement in muscle strength. Oral steroids resulted in moderate improvement in muscle strength. There have been no previously reported cases of polymyositis in association with essential cryoglobulinaemia.
\end{abstract}

(F Neurol Neurosurg Psychiatry 1993;56:317-318)

The cryoglobulinaemias are a group of disorders characterised by the presence of cryoprecipitable serum proteins. The cryoglobulinaemias are either idiopathic (essential) or occur in association with a defined connective-tissue disease, lymphoreticular neoplasia, or infectious process. The cryoprecipitate of patients with type III mixed essential cryoglobulinaemia (MEC) contains polyclonal auto-antibodies with rheumatoid factor activity. ${ }^{-}$Mixed cryoglobulins are formed by IgM antibodies to IgG or IgA. Mixed cryoglobulinaemia is characterised clinically by arthralgia, purpura, weakness and fatigue, frequently accompanied by renal involvement that can be rapidly progressive. ${ }^{2}$ The weakness seen in association with the syndrome is characteristically secondary to peripheral nerve involvement, ${ }^{3}$ and peripheral neuropathy in association with cryoglobulinaemia has been described by several authors. ${ }^{1}$ We have been unable to find any reports of weakness due to primary muscle involvement in MEC. We report a patient with MEC, who presented with a syndrome of polymyositis associated with extensive plasma cell infiltration of muscle.

\section{Case report}

A previously healthy 73 year old male presented with a syndrome of proximal muscle weakness for one year in association with a purpuric rash involving the lower extremities. $\mathrm{He}$ complained of difficulty rising from a seated position, difficulty climbing stairs, inability to rise from a squatting position, or to raise his arms above his head. He had noted some loss in muscle bulk. He also described numbness and painful paraesthesiae involving his hands and feet. In addition he had complained of episodic pain in the shoulders, knees, and feet for many years. During this same period he had developed purpura involving the lower extremities. He denied symptoms of Henoch Schonlein purpura, systemic lupus erythematosus (photosensitivity, rash, pleurisy, oral ulcers, renal disease) or thyroid disease. He also denied symptoms of Raynaud's phenomenon.

Examination revealed scattered macular purpuric maculae on both legs to mid thigh level, sparing the trunk, arms and buttocks. Intraoral examination revealed several petechiae. No lymphadenopathy, hepatosplenomegaly or active synovitis was detected.

Neck flexors, and proximal muscles in the upper and lower extremities were considerably weak (grade 3/5 MRC). Tendon reflexes were not depressed and sensory examination was normal.

Haemoglobin was $134 \mathrm{~g} / \mathrm{L}$. Westergren ESR was $44 \mathrm{mmhr}^{-1}$. Urea and creatinine were normal and there was no proteinuria. Thyroid function tests were normal. Serum protein electrophoresis revealed a polyclonal increase in gamma globulin $(37 \mathrm{~g} / \mathrm{L})$, with a superimposed monoclonal component that was identified as IgG-kappa. Screening for cold agglutinins was positive. Serum creatine kinase was moderately elevated (601 IU/1). Rheumatoid factor titre was elevated $(272 \mathrm{IU} / \mathrm{ml}$, normal $0-30 \mathrm{IU} / \mathrm{ml}$ ). Antinuclear factor titre was not elevated. Anti-DNA, anti-RNP, antiSSA and anti-SSB antibody assays were negative. A skeletal survey did not show any osteolytic lesions. Bone marrow aspirate revealed hypocellularity. Plasma cells were not increased.

Motor and sensory nerve conduction studies in the upper and lower extremities were within normal limits. Electromyographic examination, using concentric needle electrodes confirmed myopathic changes (decreased amplitude and duration of motor unit potentials, increase in polyphasia) in proximal muscle groups of the upper and lower extremities.

Light microscopic examination of a biopsy specimen from the right quadriceps femoris muscle showed necrotic and degenerating myofibres. A dense perivascular, perimysial, and endomysial inflammatory cell infiltrate comprising predominantly plasma cells (at least $75 \%$ ) was noted (fig a). Immunohistochemical examination showed that the plasma cell infiltrate expressed both kappa and 
Figure (a) Prominent plasma cell infiltrate in endomysium with atrophied and degenerating myofibres.

(Haematoxylin-eosin, $\times$ 370); (b) Most plasma cells within the endomysial inflammatory infiltrate showed immunoreactivity to anti-IgG antibody. (Avidin-biotin-peroxidase, $\times 290$ ).

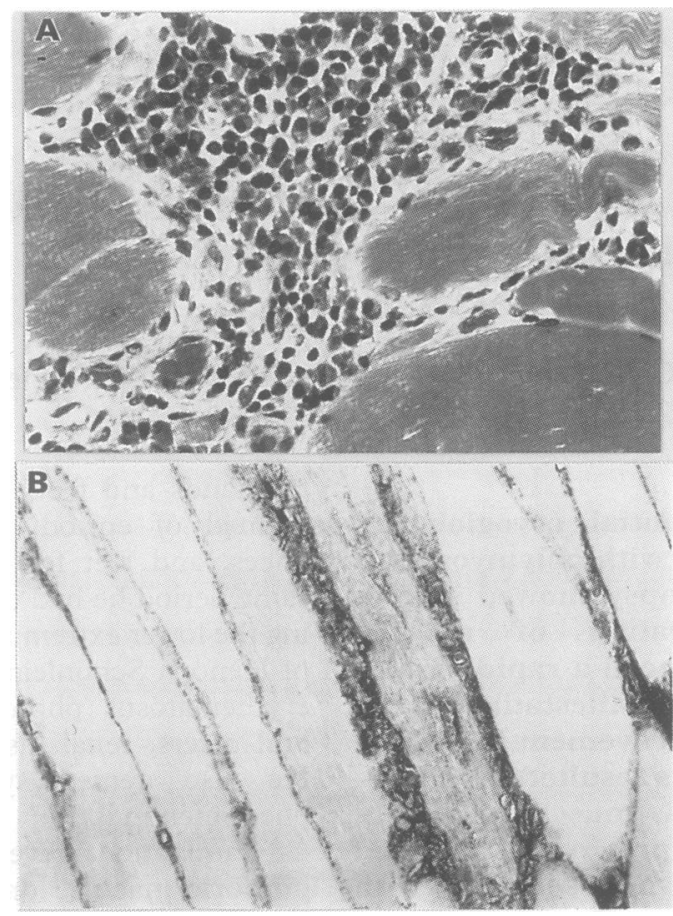

lambda light chains, indicating a polyclonal population, though most of the cells contained only IgG (fig b).

Plasmapheresis was initiated with rapid resolution of the purpura but without significant improvement in muscle strength. Oral prednisone $(30 \mathrm{mg} /$ day) was given with moderate improvement in muscle strength. Repeat protein electrophoresis five months later demonstrated a reduction in gamma globulin $(18 \mathrm{~g} / \mathrm{L})$. CK remained unchanged. During this period the patient has remained steroid dependent, and has been unable to reduce the prednisone dose to less than $10 \mathrm{mg} /$ day without experiencing a significant increase in functional disability.

\section{Discussion}

Our patient fulfills the clinical criteria for MEC. Laboratory investigations confirmed the presence in the serum of a polyclonal increase in gamma globulin, and a high titre of autoantibodies with rheumatoid factor activity. In addition cryoprecipitable proteins were demonstrated in the serum. The presenting syndrome of proximal muscle weakness due to polymyositis has not been reported previously in association with MEC. Polymyositis has been reported in association with Waldenström's macroglobulinaemia and benign monoclonal gammopathy. ${ }^{4}$ The simultaneous occurrence of the symptoms of polymyositis with the characteristic cutaneous manifestations of MEC, and the biopsy demonstration of extensive plasma cell infiltration of affected muscle, suggest that the polymyositis was a manifestation of the cryopathic syndrome. Polymyositis, irrespective of aetiology, is associated with inflammatory cellular infiltrate. Although plasma cells are present within the infiltrate, they do not comprise the major cellular subtype. Vasculitis, without plasma cell predominance, in muscle biopsy specimens from patients with peripheral neuropathy complicating MEC has been reported. ${ }^{5}$ Muscle infiltration with plasma cells was not reported in these cases. Extensive plasma cell infiltration of the muscle of the tongue has been described in association with multiple myeloma in a horse. ${ }^{6}$ In our patient, plasma cells comprised at least $75 \%$ of the inflammatory cell population in the muscle biopsy. The demonstration of polyclonal plasma cell infiltration in the muscle biopsy from our patient indicates that the underlying disease process was not secondary to a monoclonal gammopathy or myeloma. In the absence of an identifiable IgM monoclonal peak, we believe that our patient has a type III cryoglobulinaemia. Polyclonal IgM antibodies causing mixed cryoprecipitates, like rheumatoid factors, mimic anti-IgG Coombs serum. ${ }^{7}$

The mechanism of muscle fibre necrosis in this condition is unknown. It has been suggested that coating of the muscle fibre by antibody might render the muscle fibre vulnerable to attack by endomysial killer or natural killer cells. ${ }^{8}$ Alternatively muscle fibre necrosis may occur secondary to ischaemia. Brouet et $a l^{1}$ noted that minute amounts of cryoglobulins were capable of producing mechanical vascular insufficiency.

1 Brouet JC, Clauvel JP, Danon F, Klein M, Seligman M. Biologic and clinical significance of cryoglobulins: a report of 86 cases. Am $\mathfrak{f}$ Med 1974;57:775-88.

2 Meltzer M, Franklin EC, Elias K, McCluskey RT, Cooper N. Cryoglobulinemia: a clinical and laboratory study: II Cryoglobulins and rheumatoid factor activity. $A m \mathcal{F} \mathrm{Med}$ 1966;40:837-56.

3 McLeod JG, Walsh JC, Pollard JD. Neuropathies associated with paraproteinemias and dysproteinemias. In: Dyck PJ, Thomas PK, Lambert EH, Bunge R, eds. Peripheral neuropathy. Philadelphia: WB Saunders, 1984:1847-65.

4 Mastalgia FL, Ojeda VJ. Inflammatory myopathies: p1. Ann Neurol 1985;17:215-27.

5 Manganelli P, Pavesi G, Fiocchi A, et al. Peripheral neuropathy with mixed cryoglobulinemia. Recenti Prog neuropathy with mix

6 Markel MD, Dorr TE. Multiple myeloma in a horse. $\mathcal{f} \mathrm{Am}$ Vet Med Assoc 1986;188:621-3.

7 Kaplan ME, Jandl JH. The effect of rheumatoid factors and of antiglobulins on immune hemolysis in vivo. $\mathcal{f}$ Exp Med 1963;117:105.

8 Arahata K, Engel AG. Monoclonal antibody analysis of mononuclear cells in myopathies. IV: cell-mediated cytotoxicity and muscle fiber necrosis. Ann Neurol 1988;23:168-73. 